Research Article

\title{
Experimental Study of a Novel Ultrasonic Vibration-Assisted Structure for Radial Milling
}

\author{
Yu He, ${ }^{1,2}$ Lidong Ren, ${ }^{3}$ Ping Zou $\mathbb{D}^{2},{ }^{2}$ and Shuyan Wang ${ }^{4}$ \\ ${ }^{1}$ School of Urban Rail Transportation, Shanghai University of Engineering Science, Shanghai 201620, China \\ ${ }^{2}$ School of Mechanical Engineering and Automation, Northeastern University, Shenyang 110819, China \\ ${ }^{3}$ Weichai Power Co., Ltd., Weifang 261001, China \\ ${ }^{4}$ College of Mechanical Engineering, Donghua University, Shanghai 201620, China \\ Correspondence should be addressed to Ping Zou; pzou@mail.neu.edu.cn
}

Received 1 March 2021; Revised 29 March 2021; Accepted 12 April 2021; Published 8 May 2021

Academic Editor: Grzegorz Zywica

Copyright ( $) 2021 \mathrm{Yu} \mathrm{He}$ et al. This is an open access article distributed under the Creative Commons Attribution License, which permits unrestricted use, distribution, and reproduction in any medium, provided the original work is properly cited.

\begin{abstract}
A novel ultrasonic vibration-assisted structure for radial milling is proposed, and the ultrasonic vibration-assisted radial milling (UVARM) is further studied in terms of theoretical model and milling experiment. The motion and feed characteristics of UVARM are also analyzed. A special fixture is designed to construct the experimental platform of UVARM, in which the vibration is applied to the workpiece along the radial direction. The preliminary results show that with the increase of spindle speed, the milling force in both conventional cutting (CC) and UVARM experiments tends to increase. In addition, when the feed per tooth increased, the milling force increased. With the involvement of ultrasonic vibration, the milling force is significantly reduced, with the maximum reduction reaching $20 \%$. The comprehensive analysis showed that there was a decrease of about $10 \%$ to $25 \%$ in the ultrasonic case compared with the conventional method. It is also found that UVARM can inhibit the production of a built-up edge. With the ultrasonic vibration, the burrs on the processed surface are also reduced, and the grooves left by tool traces are shallower. Compared with conventional milling, the roughness value of the machined surface obtained by UVARM is reduced by $10 \%$ to $32 \%$. The experimental results also show that UVARM can effectively improve the dimensional accuracy of the workpiece.
\end{abstract}

\section{Introduction}

An ultrasonic vibration-assisted cutting (UVAC) is a kind of compound machining method which combines ultrasonic vibration with conventional machining. Compared with conventional machining (CM), UVAC can effectively improve the dimension precision, surface quality, and stability of the processing system. In the UVAC process, the tool and the workpiece have periodic contact and separation. The experimental results show that applying ultrasonic vibration is helpful to improve the cutting force, tool life, and machining accuracy for hard brittle materials machining [1]. Polyak et al. found that the quality and efficiency of the processing of refractory materials by vibration-assisted milling were significantly improved [2]. Hsu et al. also studied the UVAC of nickel-based alloy. They found that during the UVAC process, the cutting force and cutting temperature are reduced and surface roughness is smaller compared with CC. The surface accuracy and tool wear can be improved by selecting the appropriate feed rate and cutting speed [3]. Uo revealed that the machining resistance during the milling process was effectively improved in the UVAC case [4]. Pujana et al. applied ultrasonic vibration to the drilling of titanium alloy workpieces. It was found that the average drilling force decreased by $10-20 \%$ under the assisted effect of ultrasonic vibration [5]. Kuruc et al. carried out a milling test of 5083 aluminum alloy by means of the UVAC method. They found that UVAC can effectively improve the processing efficiency and the surface quality of the processed aluminum alloy [6]. Gong et al. also reported that when UVAC was used to process hard and brittle materials, better machining quality could be achieved by adopting larger cutting depth and smaller feed rate [7]. Ko and Shaw studied the surface quality of the workpiece after 
ultrasonic vibration was applied in the feed direction and vertical direction of the workpiece under the condition of high-speed milling [8]. The experiment showed that ultrasonic vibration in the feed direction had a significant impact on the processing quality. Ahmed et al. established the finite element model of ultrasonic vibration turning of chromenickel 718 to simulate the residual stress of the turning surface $[3,9]$. Zarchi et al. pointed out that the average milling force of UVAC was significantly lower than that of conventional milling by analyzing the cutting force model of one-dimensional UVAC of stainless steel AISI-420. In addition, the surface roughness was also changed under the conditions of low feed rate and high cutting speed [10-13]. Ding established a sine-sine and sine-cosine vibration model of micromilling cutting force to simulate the influence of feed rate on the cutting force and surface roughness. They also studied the influence factors of machining hardened steel under the condition of low-frequency vibration [14-17].

However, few works have been focused on the study of that when the vibration is applied to the workpiece along radial direction during ultrasonic vibration-assisted machining. The proposed work is to impose a vibration to the workpiece in the feeding direction, which makes the device a compact structure. A novel ultrasonic vibration-assisted structure for radial milling is proposed, with a special clamping device designed to set up the experimental stage for UVARM. The motion mechanism of the cutting edge of the UVARM is studied. Further investigation is also conducted to analyze the cutting tool and chip separation with different process parameters. The influence of each feed per tooth, spindle speed, vibration amplitude, and other process parameters on UVARM force, dimension precision, and surface quality was studied through a single-factor experiment. It is verified that the UVARM can effectively solve the disadvantages of ultraprecision machining such as difficulty in chip removal, severe tool wear, and high processing cost.

\section{Kinematic Analysis of Tool Trajectory of UVARM}

As shown in Figure 1, the vertical milling cutter is used to analyze the workpiece end milling process, the tool tip trajectory is a cycloid curve, as shown in Figure 2, in which $A$ is the starting point of the cutting process, $O$ is the milling cutter center for this instant, through a cutting cycle, the tool point reached point $B$ and the cutter center moved to the point $O_{1}$, and then the distance from point $A$ to point $B$ is the cutter feed per revolution.

In Figure 2, the feed rate and cutting time can directly influence the movement trajectory of the center of the milling cutter. Besides, the tool tip trajectory is also affected by the spindle speed and milling cutter radius.

The trajectory equation of the milling cutter center is $[15,16]$

$$
\begin{aligned}
& x_{0}=f_{z} \cdot N \cdot n \cdot t, \\
& y_{0}=0 .
\end{aligned}
$$

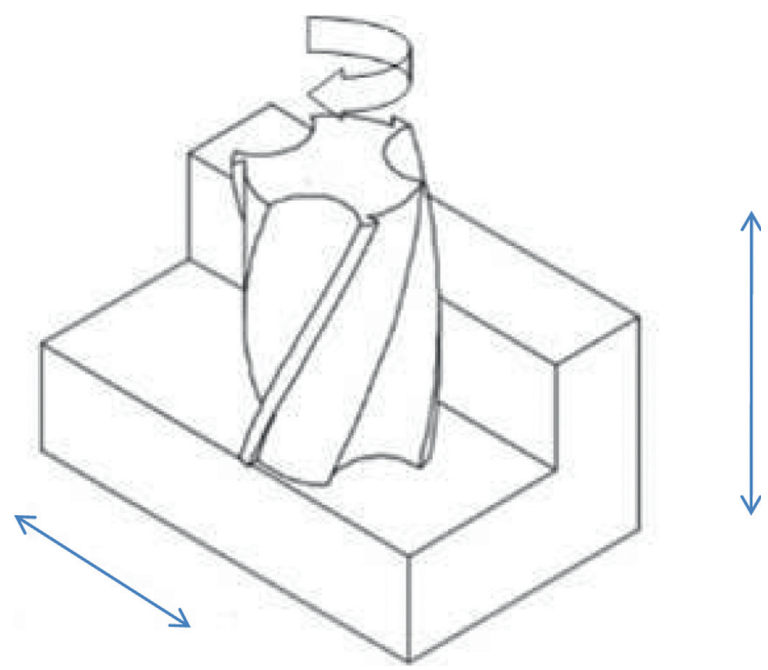

FIgURE 1: Main vibration direction in the UVARM process.

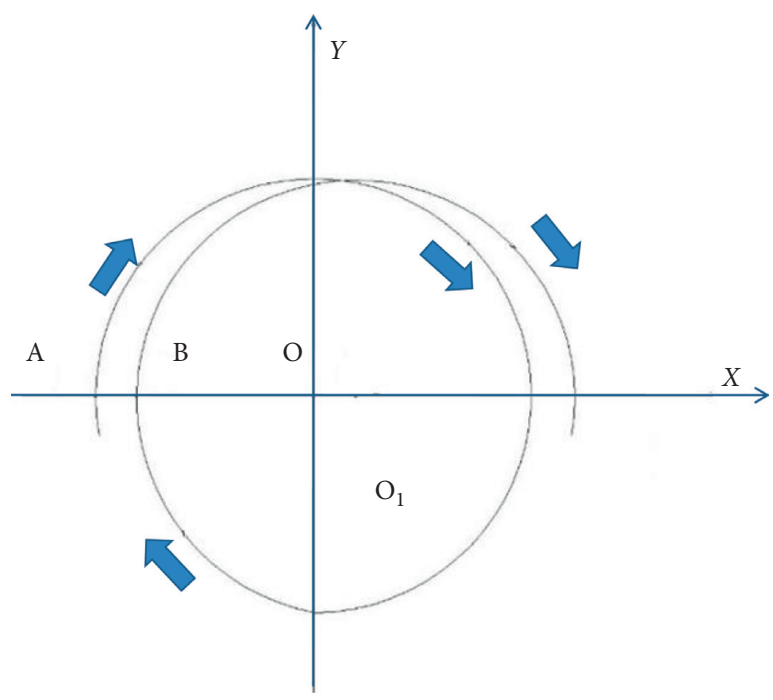

Figure 2: Path of single edge milling cutter in 1.5 cycles.

The trajectory equation of the $N^{\text {th }}$ tool tip is

$$
\begin{aligned}
& x_{n}=f_{z} \cdot N \cdot n \cdot t+r \cdot \sin (\omega \cdot t-n \cdot \varphi), \\
& y_{n}=r \cdot \cos (\omega \cdot t-n \cdot \varphi),
\end{aligned}
$$

where $f_{z}$ is the feed per tooth, $n$ is the spindle speed, $t$ is the cutting time, $r$ is the milling tool radius, $\omega$ is the angular frequency of tool rotation, $\varphi$ is the angle between adjacent tooth, and $N$ is the number of cutting edges.

A 3-edge type milling cutter is taken into consideration; therefore, $n=0,1$, and 2 . In order to observe the movement of the cutter edge during the milling process more intuitively, the feed rate was set as $40 \mathrm{~mm} / \mathrm{min}$, and the cutter radius was $8 \mathrm{~mm}$.

In addition, the trajectory equation of the milling cutter center is

$$
\begin{aligned}
& x_{0}=f_{z} N n t+A \sin (2 \pi f t+\psi), \\
& y_{0}=0 .
\end{aligned}
$$


The trajectory equation of the $N^{\text {th }}$ tool tip is

$$
\begin{aligned}
& x_{n}=f_{z} N n t+A \sin (2 \pi f t+\psi)+r \sin (\omega t-N \phi), \\
& y_{n}=r \cos (\omega t-N \phi),
\end{aligned}
$$

where $A$ is the vibration amplitude, $f$ is the vibration frequency, and $\Psi$ is the initial phase angle of the vibration signal.

The vibration-assisted milling trajectory of one of the single tool tip is simulated using MatLab as shown in Figure 3 . This work mainly focuses on the feed direction vibration, including the effect of ultrasonic vibration amplitude, feed per tooth and spindle speed on the milling force, workpiece processing precision, and dimensional precision. The milling cutter can be regarded as several small turning tools.

\section{UVARM Experiment}

3.1. UVARM Setup. The ultrasonic generator used in this study is a $2000 \mathrm{~b} / \mathrm{BDC}$ power generator (BRANSON, USA). Its maximum output power is $1100 \mathrm{~W}$ and the output frequency is $20 \mathrm{kHz}$. The ultrasonic vibrator produced by BRANSON is selected in this project. The ultrasonic vibrator is a combination of the ultrasonic transducer and ultrasonic amplitude converter, which can transform electric vibration signals more efficiently. This work applies ultrasonic vibration along the feed direction to the workpiece. The UVARM system studied in this paper is built on the TH5650 type vertical machining center. The ultrasonic vibration device can be firmly fixed on the milling machine workbench, so as to perform the UVARM. In this part, the designed UVARM system is used to carry out the comparison experiment with conventional milling of 6061-T6 aluminum alloy. The UVARM system is shown in Figure 4.

Ultrasonic vibration system is mainly composed of an ultrasonic generator, ultrasonic transducer, ultrasonic amplitude, and tools. The ultrasonic vibration device can be firmly fixed on the milling machine tool and follow the workbench to implement horizontal and vertical movement, so as to perform the UVARM. The clamping system consists of four parts: front pressure plate, back pressure plate, beam, and bracket. In order to ensure machining accuracy and reduce costs, the front and rear pressure plates are divided into two parts: upper and lower pressure plates. The front and rear pressure plates are connected to the supports through a set of screws. The ultrasonic vibration clamping system is shown in Figure 5. The 3D assembly effect of the UVARM system is shown in Figure 6.

In the figure, 1 is the cushion block, 2 is the guide rail, 3 is the slide block, 4 is the workpiece, 5 is the cover plate, 6 is the stud, 7 is the front support column, 8 is the swing rod, 9 is the ultrasonic transducer, 10 is the back support frame, 11 is the beam, 12 is the fixed block, 13 is the back support block, 14 is the bottom plate, and 15 is the front support block. The experimental setup is shown in Figure 7.

The vibration device is analyzed using the FEA method with Abaqus software. In this analysis, the material properties of each part are set as Table 1 . The $40^{\text {th }}$-order natural

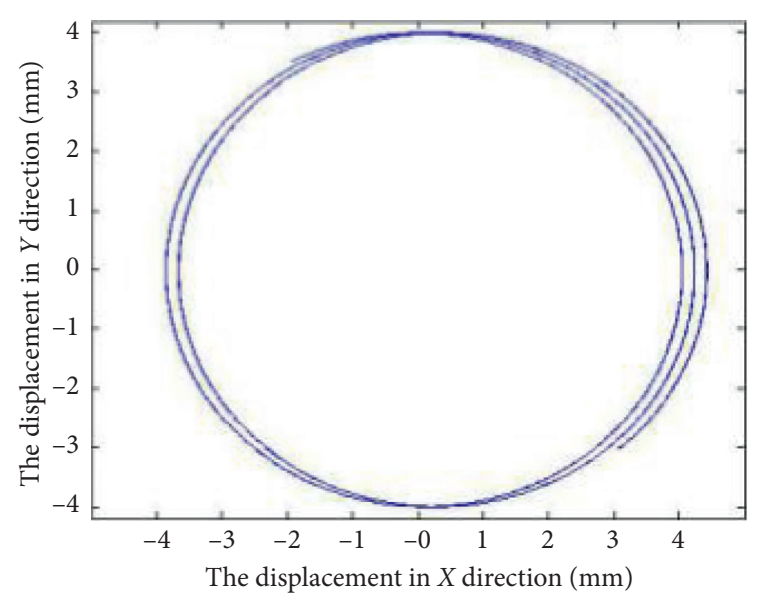

FIGURE 3: UVARM path diagram of the single blade.

frequency of the vibration device model and the corresponding vibration mode are extracted. The $30^{\text {th }}$ order natural frequencies of the selected model are shown in Table 2.

The $40^{\text {th }}$-order vibration mode of the vibration device model is presented in the form of a color cloud diagram. For the convenience of comparative study, the typical $6^{\text {th }}$-order vibration mode of the $40^{\text {th }}$-order vibration mode is extracted, and its form is shown in Figure 8. Different colors on the cloud map represent different deformation effects on the model. From blue to red, the darker the color is, the more obvious the deformation effect is, that is, the more obvious the displacement changes of the corresponding parts of the model are. In the actual process of UVARM, in order to avoid the loss of energy, only radial vibration of the vibration device is required in the milling process, and no vibration in other directions is required. Therefore, only radial displacement is required for the joints in the model of the vibration device.

Through a comparative study on the $40^{\text {th }}$-order vibration mode diagram of the vibration device, it is found that the vibration mode of the vibration device model in the $16^{\text {th }}$ and $19^{\text {th }}$ orders is relatively ideal; that is, the vibration corresponding to the $16^{\text {th }}$ and $19^{\text {th }}$ orders has radial vibration but no unnecessary vibration in other directions. It can be seen from Table 2 that the natural frequency corresponding to the $16^{\text {th }}$ order is $16608 \mathrm{~Hz}$. The natural frequency of the $19^{\text {th }}$ order is $19995 \mathrm{~Hz}$, which is very close to the $20 \mathrm{kHz}$ frequency emitted by the vibration device, so the vibration device can reach the resonance state. It can be found from the $19^{\text {th }}$-order vibration profile of the vibration device model that the design of connecting the workpiece directly to the front of the amplitude-changing bar through the doubleheaded screw column satisfies the requirement of UVARM in vibration mode.

This study uses the Kistler9257B type quartz piezoelectric dynamometer (Alpine Instrument, Swiss), the model of the charge amplifier is Kistler5070A multichannel amplifier, data acquisition system is a USB Kistler 5697A type high-speed acquisition system, and the data analysis system is type Kistler2825A DynoWare software. In order to 


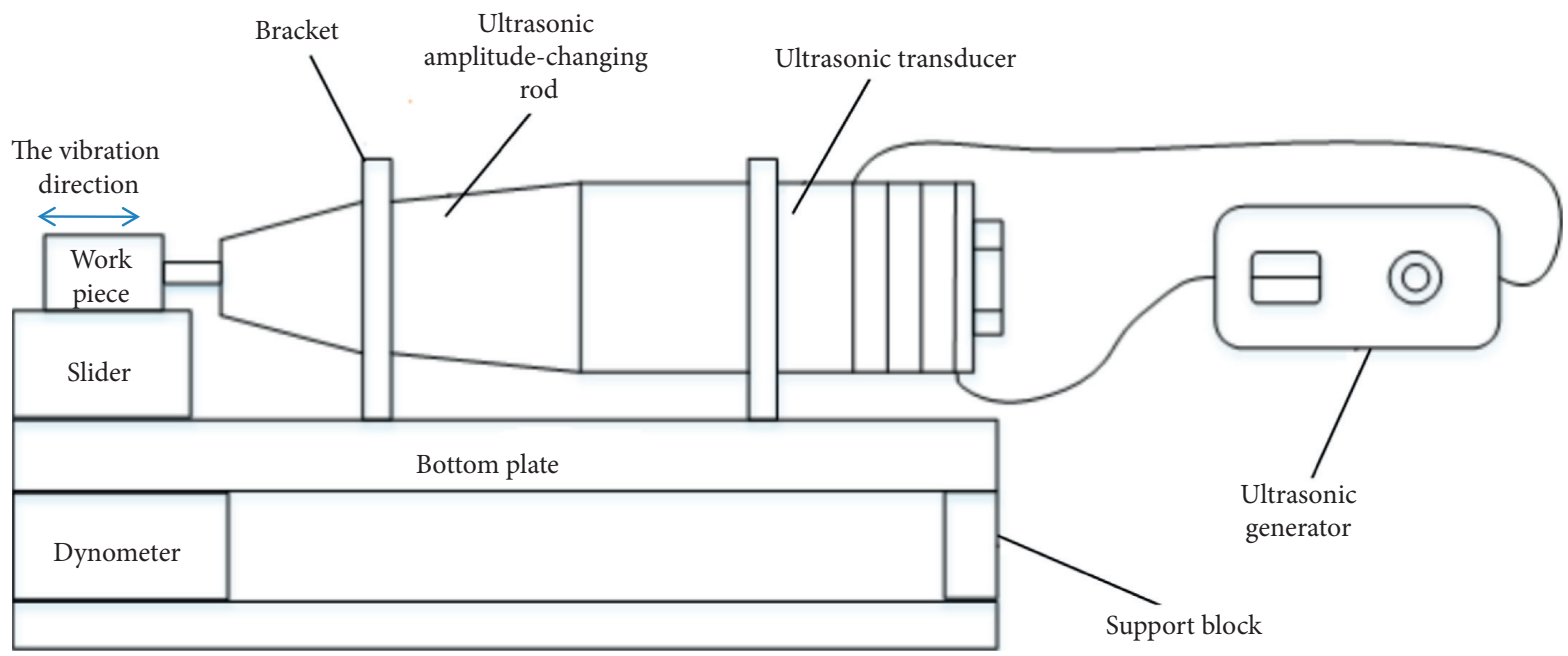

FIgURE 4: Schematic diagram of the ultrasonic vibration system.

measure the surface roughness of the workpiece, a Micromeasure 3D profiler was used. The sampling area of this 3D contour instrument is flexible. It can analyze areas of $0.1 \times 0.1 \mathrm{~mm}, 0.2 \times 0.2 \mathrm{~mm}$, and $0.3 \times 0.3 \mathrm{~mm}$. In the actual measurement, the measurement area should be set according to the actual situation. The measured surface in this test is flat and the machining area is large. $0.2 \times 0.2 \mathrm{~mm}$ of the processed surface is selected for sampling analysis in this survey. In order to observe the surface morphology of the workpiece, this experiment also adopted a VHX-1000e ultrasonic depth of 3D display system imported from Japan.

The workpiece used in this experiment is the 6061-T6 aluminum alloy block of $25 \times 25 \times 30 \mathrm{~mm}$. In order to reduce the material waste and ensure the convenience of clamping, a $9 \mathrm{~mm}$ through-hole is generated at the end of the workpiece and different workpieces are numbered. Then, the workpiece is connected with the amplitude-changing rod by a double-headed bolt. The 3-tooth ultrahard straight shank end mill with a diameter of $8 \mathrm{~mm}$ was selected in this experiment. The specific parameters are shown in Table 3.

3.2. The Milling Force Analysis in UVARM. Generally, the milling force acting on the milling cutter can be divided into circular force, feed resistance, and depth of cut resistance. According to the feed characteristics analysis in the second section, the parameter selection should meet $f_{z} \leq 2 \mathrm{~A}$. Specific experimental parameters are set as shown in Table 4.

The effect of ultrasonic amplitude, spindle speed, and feed per tooth on milling force was studied by a single-factor experiment. The experiment can be divided into three steps. (1) The ultrasonic amplitude and the feed per tooth remain unchanged, and the influence of spindle speed on the milling force is explored. (2) The ultrasonic amplitude and spindle speed remain unchanged, and the influence of the feed per tooth on the milling force is explored. (3) The spindle speed and feed per tooth remain unchanged, and the influence of ultrasonic amplitude on milling force is explored. The specific experimental scheme is shown in Table 5.

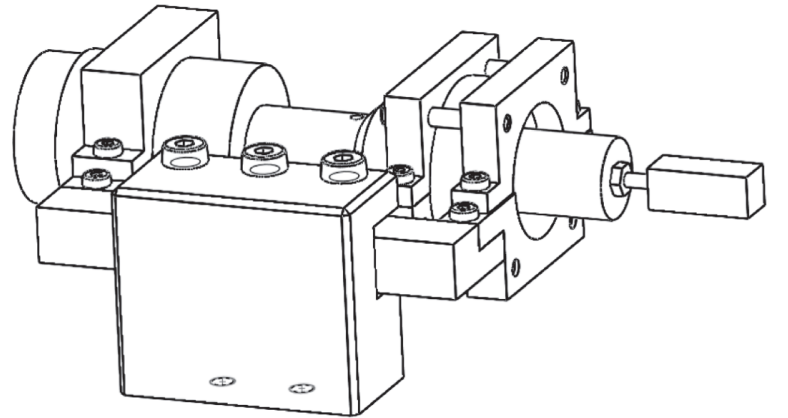

Figure 5: Special fixture structure for ultrasonic vibration system.

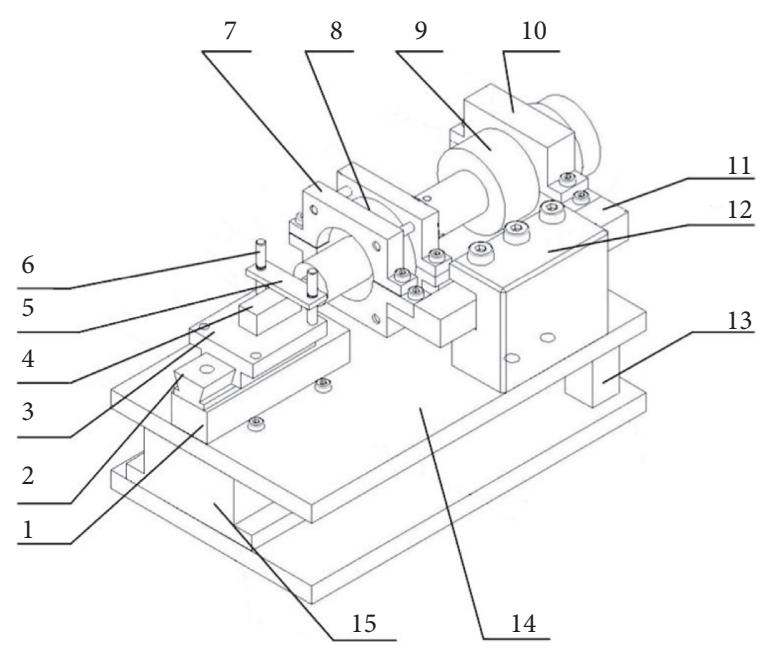

FIGURE 6: 3D assembly effect drawing of UVARM system.

The process parameters are set as spindle speed $2000 \mathrm{~min}^{-1}$, depth of cut is $0.3 \mathrm{~mm}$, different amplitudes are 0 and $15 \mu \mathrm{m}$, and the feed per tooth is $6 \mu \mathrm{m}$ and $8 \mu \mathrm{m}$, respectively. In UVARM, ultrasonic amplitude, feed per tooth, and spindle speed have a significant influence on the amplitude of milling force. The advantages of UVARM are 


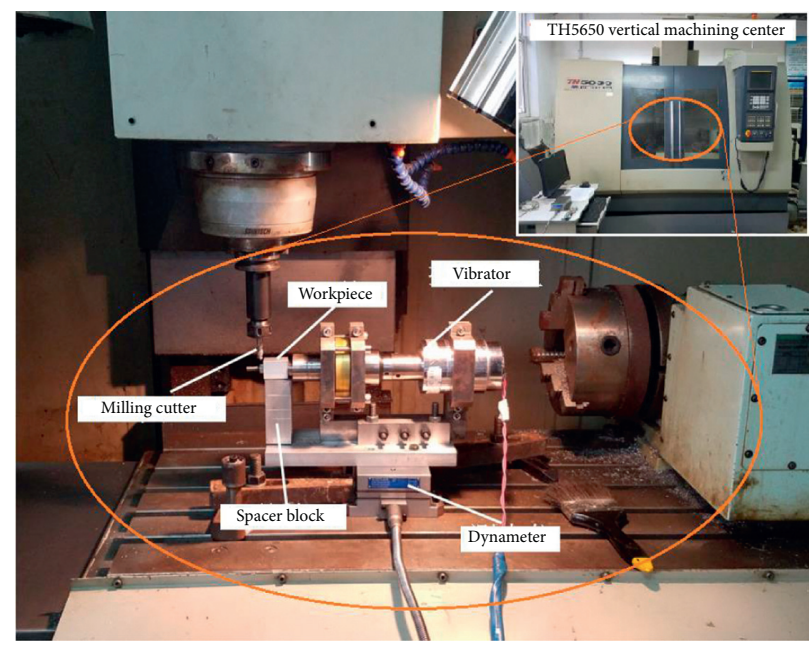

FIGURE 7: General assembly diagram of the UVARM system.

TABle 1: Material properties.

\begin{tabular}{lcccc}
\hline & Material & Density $\left(\mathrm{kg} / \mathrm{m}^{3}\right)$ & Young's modulus $(\mathrm{GPa})$ & Poisson ratio \\
\hline Piezo & PZT-4 & $7.45 \cdot 10^{-9}$ & 76.5 & 0.3 \\
Amplitude-changing bar & Titanium alloy & $4.43 \cdot 10^{-9}$ & 113.8 & 0.34 \\
Stud & $\# 45$ & $7.85 \cdot 10^{-9}$ & 206 & 0.25 \\
Workpiece & $6061-\mathrm{T} 6$ & $2.80 \cdot 10^{-9}$ & 70 & 0.33 \\
\hline
\end{tabular}

TABLe 2: Natural frequency of vibration device model.

\begin{tabular}{|c|c|c|c|c|c|c|c|}
\hline Order & Frequency & Order & Frequency & Order & Frequency & Order & Frequency \\
\hline 1 & 1127.7 & 11 & 9921.3 & 21 & 22956 & 31 & 40708 \\
\hline 2 & 1128.8 & 12 & 9926.6 & 22 & 27107 & 32 & 40732 \\
\hline 3 & 2271.6 & 13 & 15986 & 23 & 27208 & 33 & 41868 \\
\hline 4 & 2287.2 & 14 & 16026 & 24 & 28262 & 34 & 43379 \\
\hline 5 & 4275.3 & 15 & 16174 & 25 & 30318 & 35 & 44612 \\
\hline 6 & 4280.6 & 16 & 16608 & 26 & 30346 & 36 & 44622 \\
\hline 7 & 4789.1 & 17 & 18411 & 27 & 31124 & 37 & 46079 \\
\hline 8 & 5241.8 & 18 & 18432 & 28 & 36878 & 38 & 46102 \\
\hline 9 & 8305.8 & 19 & 19995 & 29 & 39241 & 39 & 46554 \\
\hline 10 & 9594.6 & 20 & 22949 & 30 & 39243 & 40 & 46652 \\
\hline
\end{tabular}

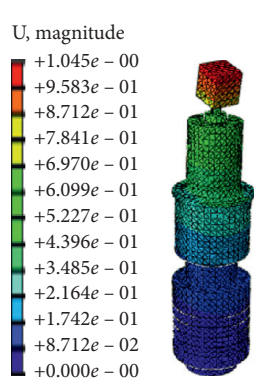

(a)

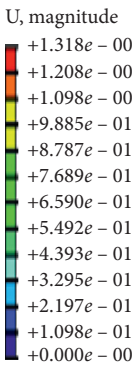

(b)
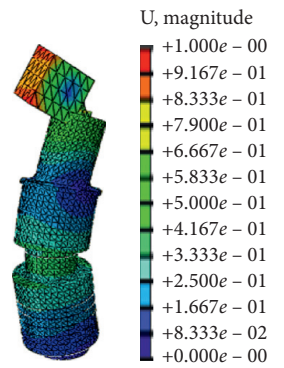

(c)

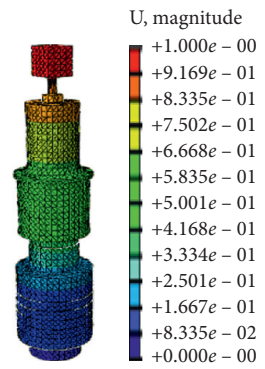

(d)

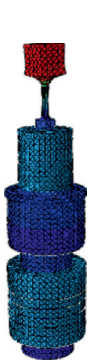

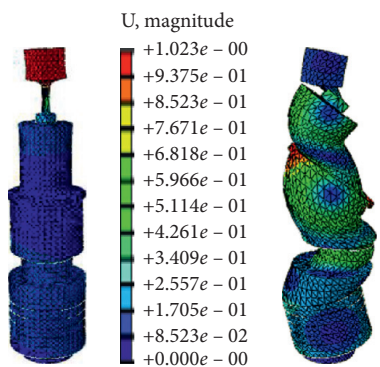

(e)

(f)

FIGURE 8: Vibration pattern diagram of the vibration device model. (a) $1^{\text {st }}$ order. (b) $6^{\text {th }}$ order. (c) $9^{\text {th }}$ order. (d) $16^{\text {th }}$ order. (e) $19^{\text {th }}$ order. (f) $30^{\text {th }}$ order.

TABle 3: Tool parameters.

\begin{tabular}{lccc}
\hline Cutter material & Diameter $(\mathrm{mm})$ & Spiral angle of the cutter $\left(^{\circ}\right)$ & Cutter tooth no. \\
\hline High-speed steel & 8 & 45 & 3 \\
\hline
\end{tabular}


TABLE 4: Level of experimental factors.

\begin{tabular}{lccc}
\hline Case & Amplitude $(\mu \mathrm{m})$ & Spindle speed $\left(\mathrm{min}^{-1}\right)$ & Feed per tooth $(\mu \mathrm{m})$ \\
\hline 1 & 0 & 800 & 2 \\
2 & 10 & 1000 & 4 \\
3 & 15 & 1500 & 6 \\
4 & 20 & 2000 & 8 \\
5 & 25 & 2500 & 10 \\
\hline
\end{tabular}

TABLe 5: Single-factor experimental set.

\begin{tabular}{|c|c|c|c|c|c|}
\hline Case & Feed per tooth $(\mu \mathrm{m})$ & Feed rate $(\mathrm{mm} / \mathrm{min})$ & Spindle speed $\left(\mathrm{min}^{-1}\right)$ & Depth of cut $(\mathrm{mm})$ & Amplitude $(\mu \mathrm{m})$ \\
\hline 1 & 6 & 36 & 2000 & 0.3 & 0 \\
\hline 2 & 6 & 36 & 2000 & 0.3 & 10 \\
\hline 3 & 6 & 36 & 2000 & 0.3 & 15 \\
\hline 4 & 6 & 36 & 2000 & 0.3 & 20 \\
\hline 5 & 6 & 36 & 2000 & 0.3 & 25 \\
\hline 6 & 6 & 14.4 & 800 & 0.3 & 0 \\
\hline 7 & 6 & 18 & 1000 & 0.3 & 0 \\
\hline 8 & 6 & 27 & 1500 & 0.3 & 0 \\
\hline 9 & 6 & 45 & 2500 & 0.3 & 0 \\
\hline 10 & 6 & 14.4 & 800 & 0.3 & 15 \\
\hline 11 & 6 & 18 & 1000 & 0.3 & 15 \\
\hline 12 & 6 & 27 & 1500 & 0.3 & 15 \\
\hline 13 & 6 & 45 & 2500 & 0.3 & 15 \\
\hline 14 & 2 & 12 & 2000 & 0.3 & 0 \\
\hline 15 & 4 & 24 & 2000 & 0.3 & 0 \\
\hline 16 & 8 & 48 & 2000 & 0.3 & 0 \\
\hline 17 & 10 & 60 & 2000 & 0.3 & 0 \\
\hline 18 & 2 & 12 & 2000 & 0.3 & 15 \\
\hline 19 & 4 & 24 & 2000 & 0.3 & 15 \\
\hline 20 & 8 & 48 & 2000 & 0.3 & 15 \\
\hline 21 & 10 & 60 & 2000 & 0.3 & 15 \\
\hline
\end{tabular}

further proved by experimental analysis with and without ultrasonic vibration when milling 6061-T6 aluminum alloy, as well as the influence of spindle speed and feed per tooth on milling force.

In this section, the influence of spindle speed on milling force during processing is analyzed and studied by selecting different spindle speeds. In the experiment, the feed per tooth was $6 \mu \mathrm{m}$, the ultrasonic amplitude was $15 \mu \mathrm{m}$, and the milling depth was $0.3 \mathrm{~mm}$. The curve of milling force changing with spindle speed is shown in Figure 9 to Figure 12 .

It can be found that the component force in $X, Y$, and $Z$ directions and the total milling force $F$ all show an increasing trend with the spindle speed changed. In the process of spindle speed increasing from $800 \mathrm{~min}^{-1}$ to $2500 \mathrm{~min}^{-1}, \mathrm{Fx}$ and $\mathrm{Fz}$ showed an increasing trend, but the increase was not obvious. For example, under normal milling conditions, the milling force component in the $X$ direction increased from $23.08 \mathrm{~N}$ to $33.21 \mathrm{~N}$, which increased by $43.89 \%$. Under the condition of the ultrasonic amplitude of $15 \mu \mathrm{m}$, the milling force component in the $X$ direction increased from $20.42 \mathrm{~N}$ to $27.43 \mathrm{~N}$, which increased by $34.33 \%$. In addition, under the condition of ultrasonic machining and CC, respectively, the milling force in the $X$ direction decreased by $11.5 \%$ and $17.7 \%$, and that in the $Z$ direction decreased by $11.7 \%$ and $20.4 \%$. In the process of spindle speed increasing from

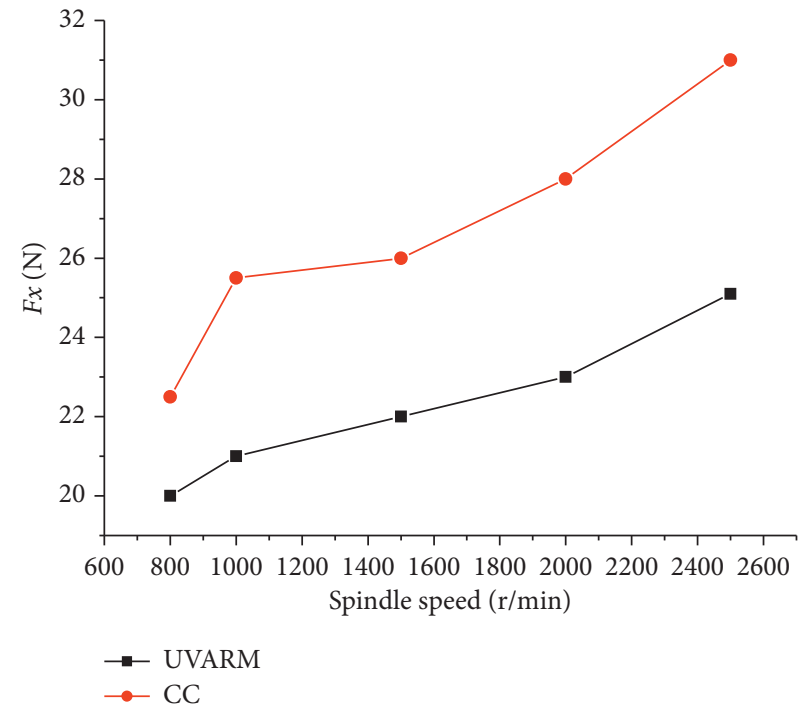

FIGURE 9: Fx changes with the spindle speed.

$800 \mathrm{~min}^{-1}$ to $2500 \mathrm{~min}^{-1}$, Fy directional milling force increases significantly. Under normal milling conditions, the milling force in the $Y$ direction increased from $26.82 \mathrm{~N}$ to $44.83 \mathrm{~N}$, which increased by $67.2 \%$. Under the condition 


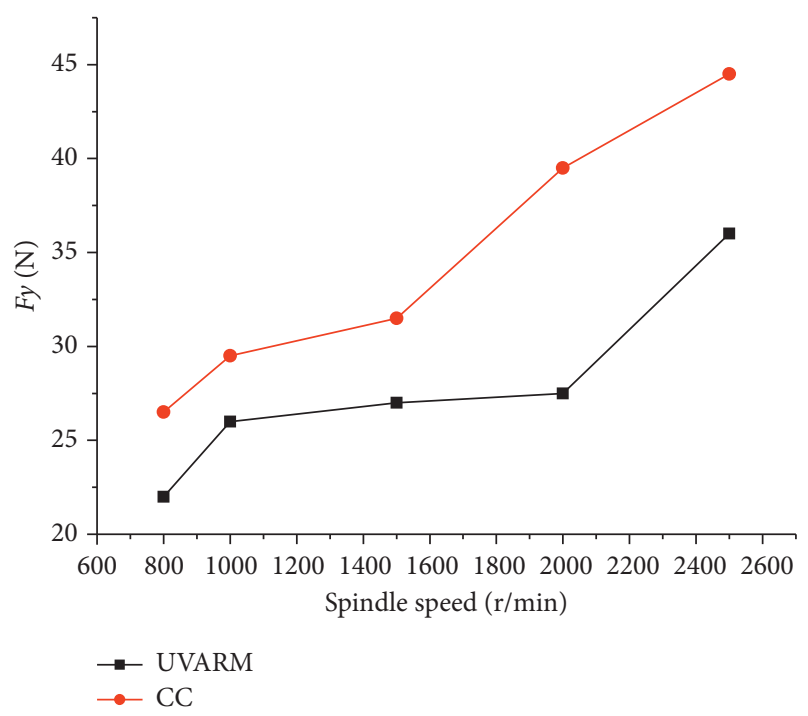

Figure 10: Fy changes with the spindle speed.

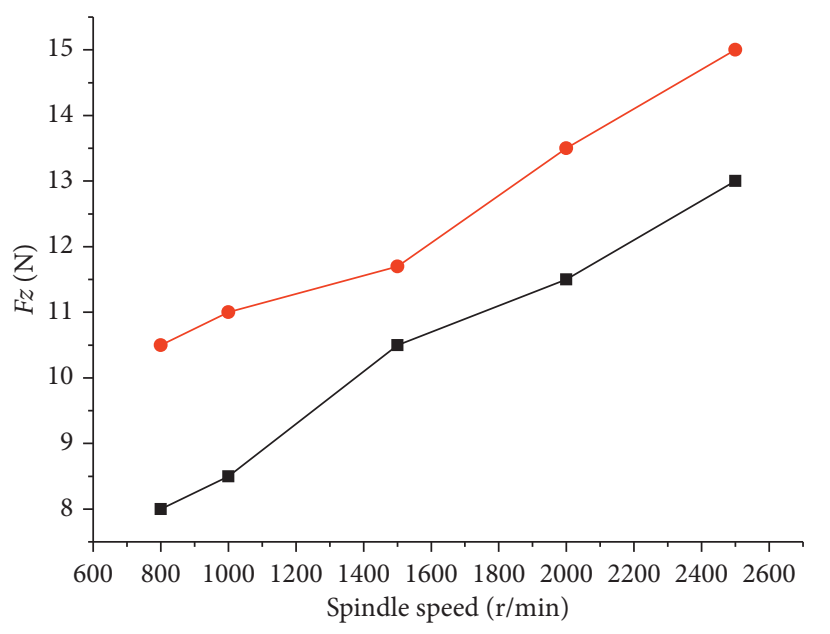

$\rightarrow-$ UVARM

$\rightarrow$ CC

FIGURE 11: $F z$ changes with the spindle speed.

when the ultrasonic amplitude was $15 \mu \mathrm{m}$, the milling force in the $Y$ direction increased from $22.21 \mathrm{~N}$ to $37.04 \mathrm{~N}$, which increased by $66.7 \%$. Moreover, under the condition of ultrasonic machining and CC, the $Y$ direction milling force decreased by $12.7 \%$ and $23.8 \%$, respectively. This is due to the ultrasonic vibration leading to more fluidity chip removal. Compared with CC, the resultant force of UVARM is improved significantly, and the maximum reduction of milling force is $19.6 \%$, which fully shows that the milling force increased by material rheological rate can be effectively reduced under the processing condition of higher spindle speed with the involvement of ultrasonic vibration.

In this section, the influence of feed per tooth on milling force during the processing is analyzed by selecting different types of feed per tooth. Among them, $2000 \mathrm{~min}^{-1}$ of spindle speed was selected in the experiment, the ultrasonic

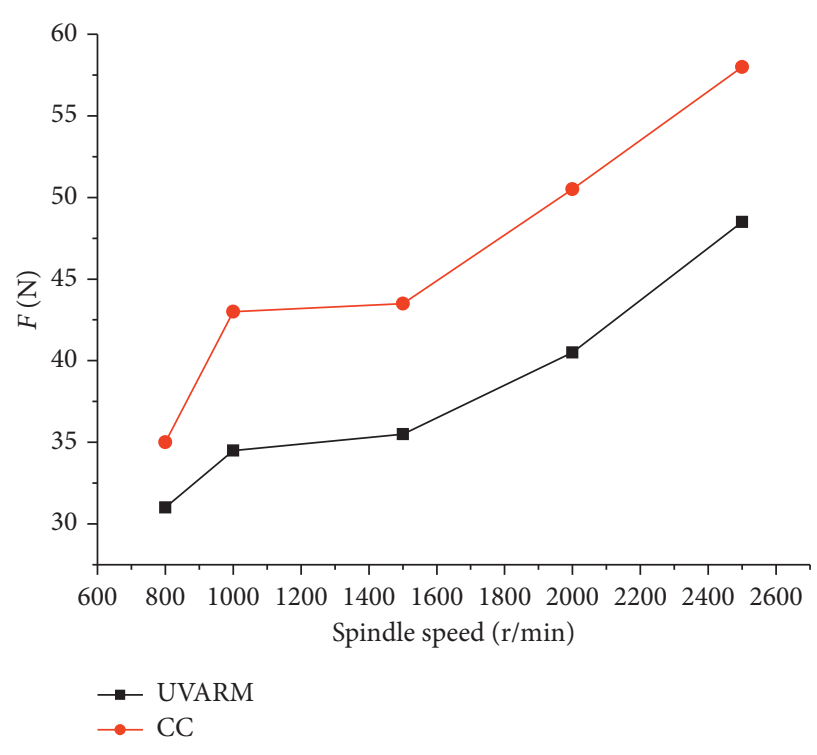

FIGURE 12: $F$ changes with the spindle speed.

amplitude was selected as $15 \mu \mathrm{m}$, and the depth of cut was selected as $0.3 \mathrm{~mm}$. The regular behavior of milling force changing with the feed per tooth is shown in Figures 13 to 16. It can be found that when the ultrasonic amplitude is $15 \mu \mathrm{m}$, the spindle speed is $2000 \mathrm{~min}^{-1}$, and the depth of cut is $0.3 \mathrm{~mm}$, with the increase of the feed per tooth, the milling component force and the total milling force in $X, Y$, and $Z$ directions in the UVARM and conventional milling are gradually increasing with the increase of feed per tooth. In the process of the feed per tooth increasing from $2 \mu \mathrm{m}$ to $10 \mu \mathrm{m}$, the milling component $F x$ in the $X$ direction showed an increasing trend, but the difference between them was not significant, and the maximum difference was less than $5 \mathrm{~N}$. For example, under normal milling conditions, the milling force in the $X$ direction increased from $19.67 \mathrm{~N}$ to $28.21 \mathrm{~N}$, which increased by $43.4 \%$. Under the condition of the ultrasonic amplitude of $15 \mu \mathrm{m}$, the milling force in the $X$ direction increased from $18.35 \mathrm{~N}$ to $26.23 \mathrm{~N}$, which increased by $42.9 \%$. Moreover, under the condition of ultrasonic machining and CC, respectively, the milling force in the $X$ direction decreased by $6.7 \%$ and $18.7 \%$, and the change tendency of the milling force in the $Z$ direction was similar to that in the $X$ direction. When the feed per tooth is less than $6 \mu \mathrm{m}$, the UVARM is not significantly different from that of normal milling in the $Y$ direction. When the feed per tooth is greater than $6 \mu \mathrm{m}$, the advantages of UVARM are gradually highlighted. Specifically, under normal milling conditions, the milling force in the $Y$ direction increased from $21.94 \mathrm{~N}$ to $35.65 \mathrm{~N}$, which increased by $62.5 \%$. Under the processing condition with the ultrasonic amplitude of $15 \mu \mathrm{m}$, the milling force in the $Y$ direction increased from $20.83 \mathrm{~N}$ to $30.45 \mathrm{~N}$, which increased by $46.2 \%$. In addition, under the condition of ultrasonic machining and CC, respectively, the milling force in the $Y$ direction decreased by $5.1 \%$ and $14.6 \%$. Compared with conventional milling, the resultant force of UVARM has been improved significantly, and the maximum reduction of milling force is $18.8 \%$, which fully shows 


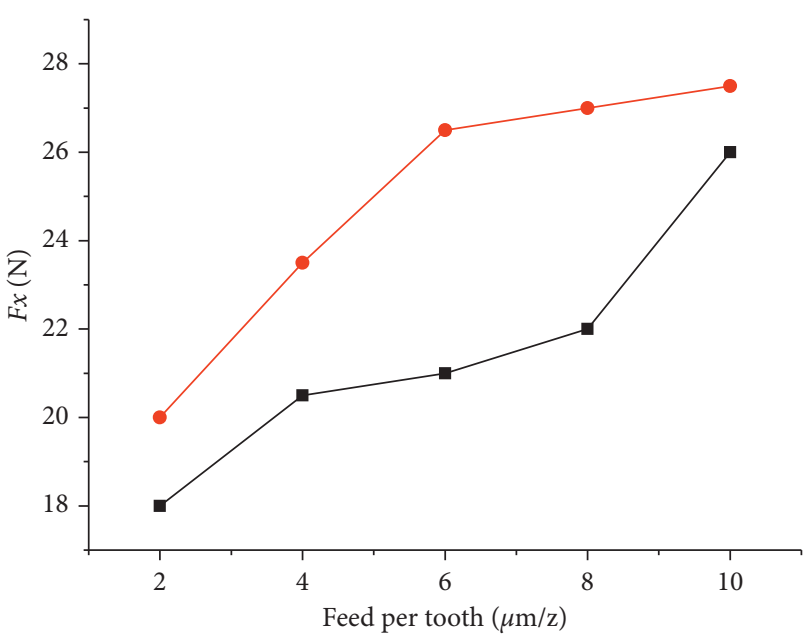

$\rightarrow-$ UVARM

$\rightarrow$ CC

Figure 13: Fx changes with feed per tooth.

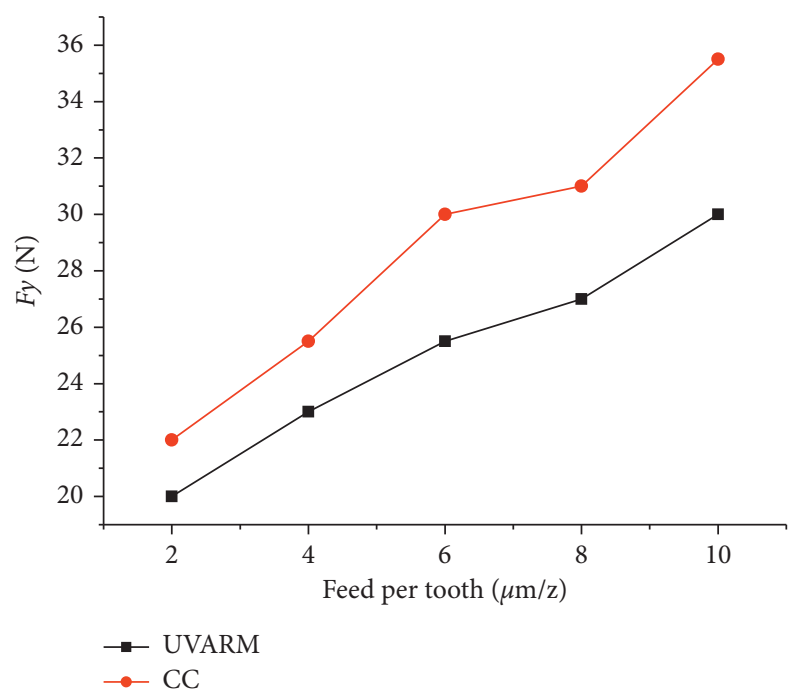

Figure 14: Fy changes with feed per tooth.

that under the assisted effect of ultrasonic vibration, the milling force of each tooth can be effectively reduced due to the increase of feed rate.

In this section, different ultrasonic amplitudes are selected to analyze the influence of ultrasonic amplitudes on the milling force during processing. In the experiment, the feed per tooth was $6 \mu \mathrm{m}$, the spindle speed was $2000 \mathrm{~min}^{-1}$, and the depth of cut was $0.3 \mathrm{~mm}$. The behavior of milling force changing with ultrasonic amplitude is shown in Figures 17 to 20 . It can be found that the milling force in the $X$, $Y$, and $Z$ directions and the total milling force $\mathrm{F}$ decreased with the increase of the ultrasonic amplitude, with certain feeding on each tooth, the spindle speed, depth of cut, etc. Among them, the biggest drop of $X$ direction of the milling force component was $16.6 \%$, the $Y$ direction of the milling force component of the largest decline amplitude was $16.5 \%$, the biggest drop in the $Z$ direction of the milling force

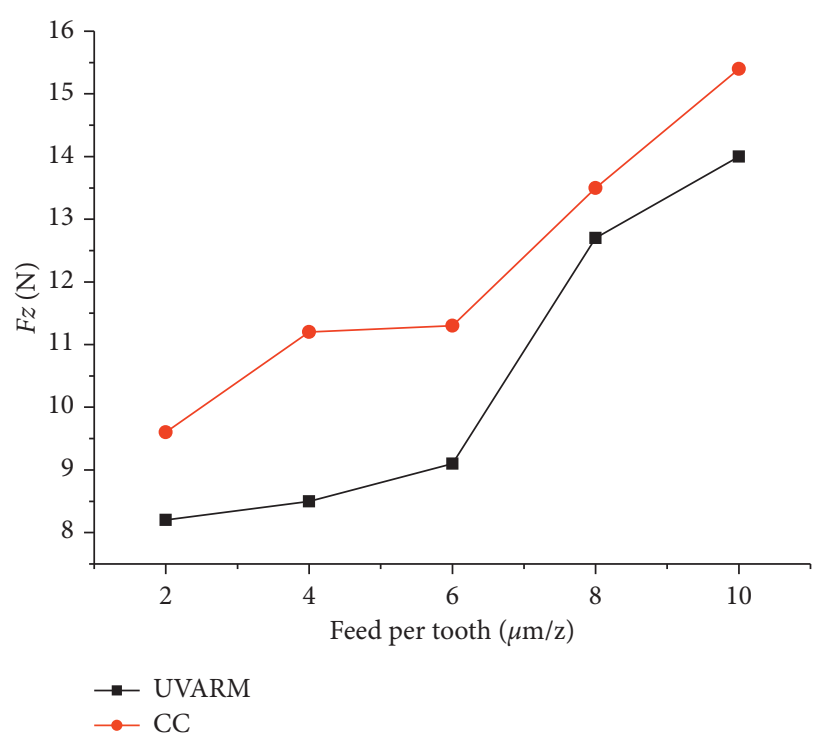

Figure 15: $F z$ changes with feed per tooth.

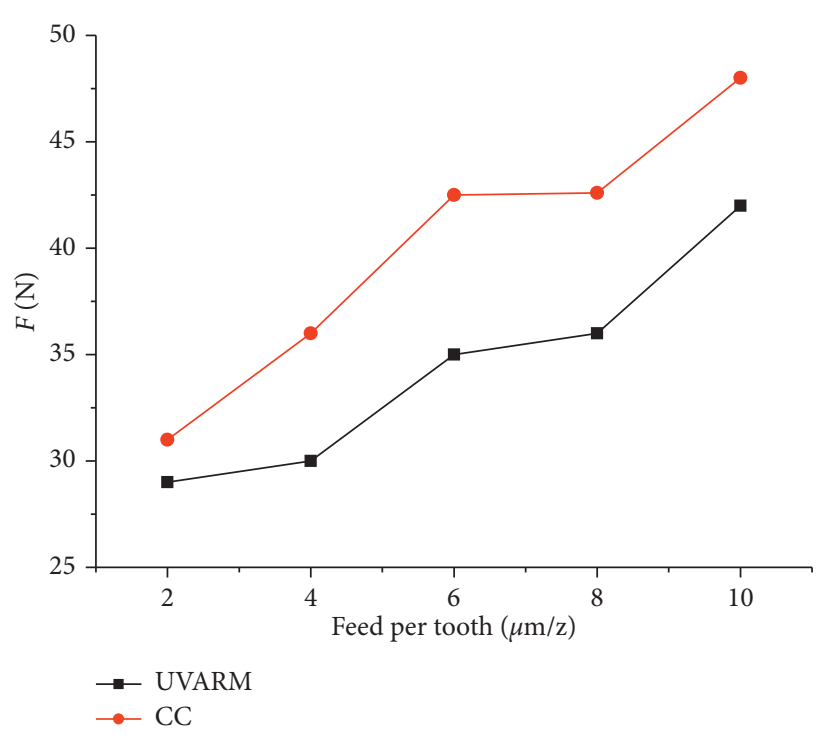

FIgURE 16: $F$ changes with feed per tooth.

component value was $20.4 \%$, and the maximum drop of the resultant milling force $\mathrm{F}$ is $20.7 \%$, which fully shows that compared with conventional milling, under the action of ultrasonic vibration, the milling force during milling can be effectively reduced.

To sum up, under the assisted effect of ultrasonic vibration, the milling force in $X, Y$, and $Z$ directions and the resultant milling force in the milling process are lower than those in normal milling. Moreover, compared with normal milling, the vibration milling force in UVARM increases relatively slowly and the increased range is relatively small. According to the analysis, the reason for this phenomenon is that the application of ultrasonic vibration in the milling process causes the vibration of the workpiece to produce a greater acceleration, which to a certain extent inhibits the formation of built-up edge and the burrs. At the same time, 


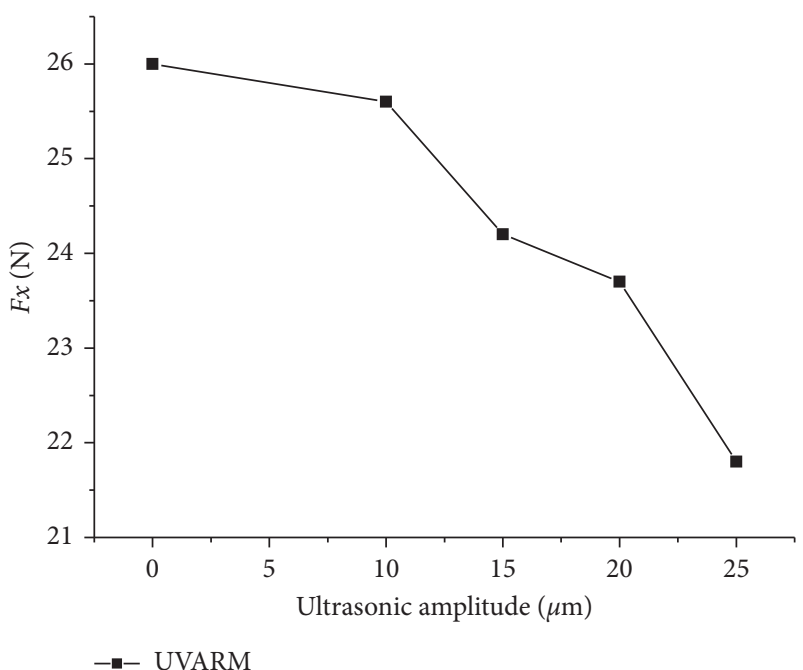

Figure 17: Fx changes with ultrasonic amplitude.

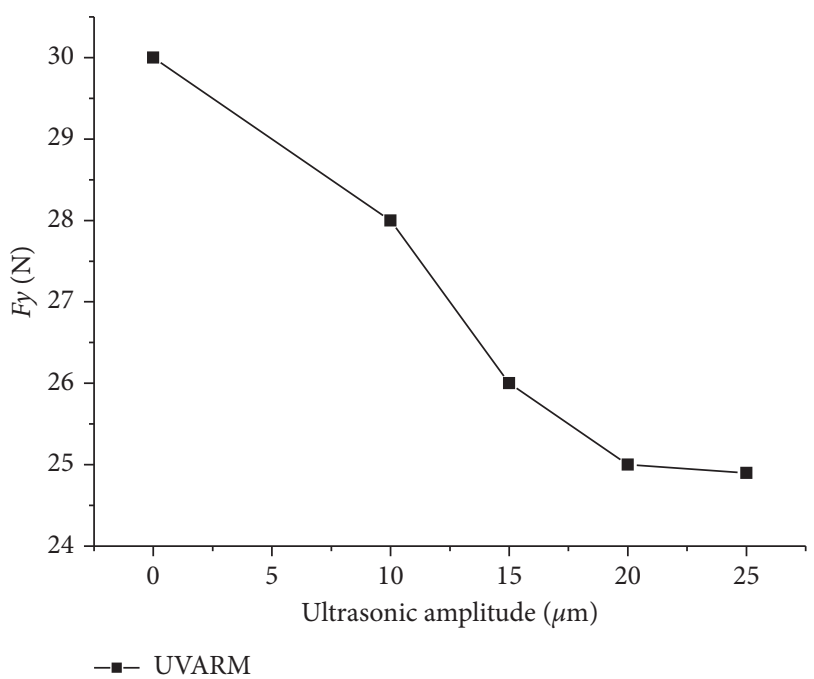

FIGURE 18: Fy changes with ultrasonic amplitude.

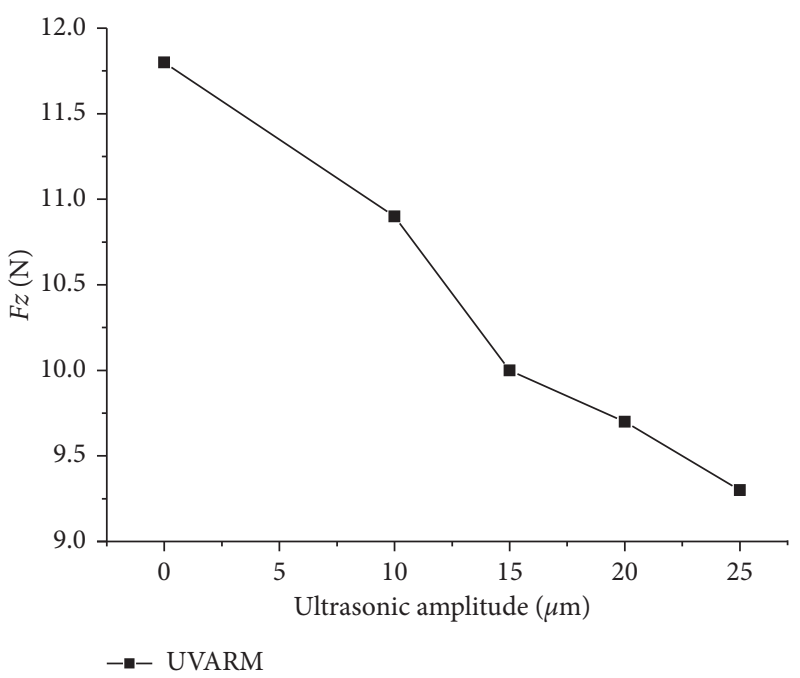

Figure 19: $F z$ changes with ultrasonic amplitude.

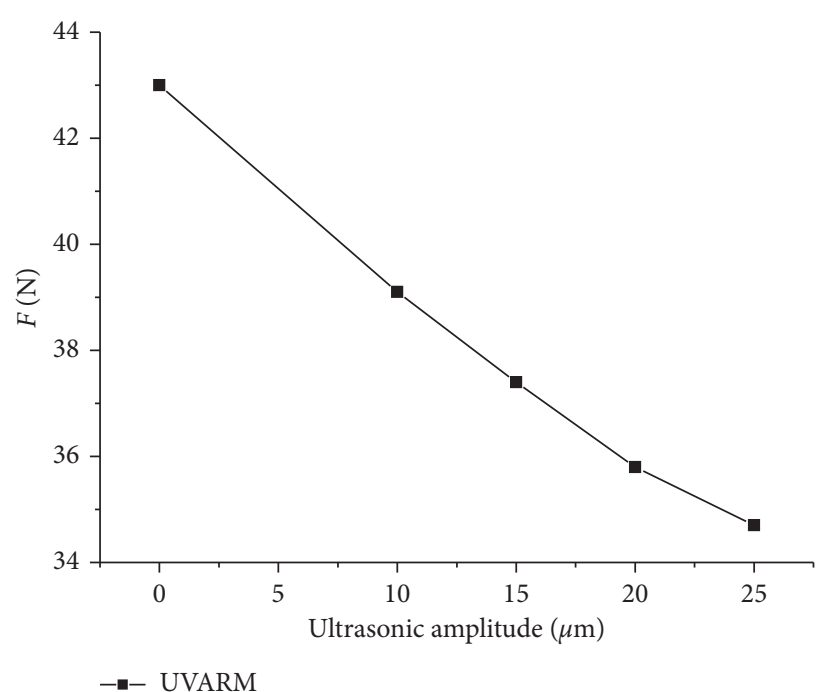

FIgURe 20: $F$ changes with ultrasonic amplitude.

UVARM turns the traditional continuous milling method into intermittent contact between the tool and the workpiece, which is conducive to chip removal. When the tool and chip are separated, a large pulse force will be generated between the workpiece and the tool. The chip area of the workpiece is relatively easy to generate fatigue damage under the action of this pulse force, which reduces the stress. Therefore, the milling force generated in the milling process after ultrasonic vibration is reduced.

3.3. The Surface Quality Analysis in UVARM. In this section, groove milling experiments are conducted to study the surface roughness of the bottom surface of the groove formed by the bottom milling edge of the milling cutter and to compare the surface roughness $\mathrm{Sa}$ formed by the UVARM. The main research object is 6061-T6 aluminum alloy milling surface roughness, and the ultrasonic vibration-assisted radial milling work stage is independently designed. By single-factor experiment, the comparison of ultrasonic vibration-assisted radial milling with conventional milling under the same processing conditions was investigated. The effect of spindle rotation, feed per tooth, and ultrasonic amplitude on the surface roughness of the machined surface is analyzed, which accordingly verified the superiority of ultrasonic vibration-assisted radial milling.

As shown in Figure 21, the workpiece surface morphology of the UVARM and CC is presented. Among them, the experiment parameters are set as follows: feed per tooth is $6 \mu \mathrm{m}$, the selected spindle speed is $2000 \mathrm{~min}^{-1}$, and the ultrasonic amplitude is $15 \mu \mathrm{m}$. From Figure 21, it can be found that there is an obvious scratch on the workpiece surface and the surface texture is relatively rough. In addition, more obvious burrs are found along the CC groove edge, and machining defects are significant. In contrast, the bottom surface of the groove obtained by UVARM is relatively smooth, and the surface texture is regular. At the same time, UVARM has fewer burrs on the edge of the groove. The cause of the difference is that the effect of 


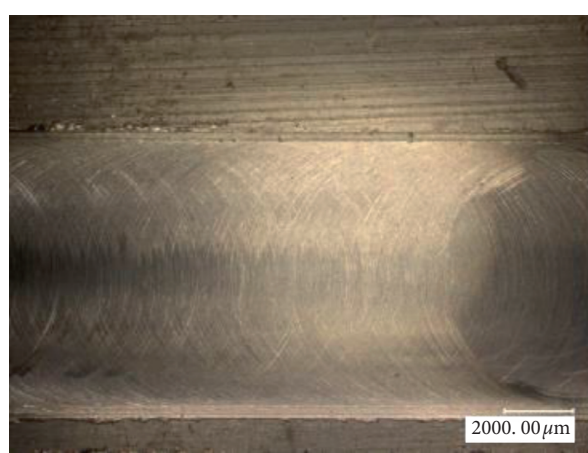

(a)

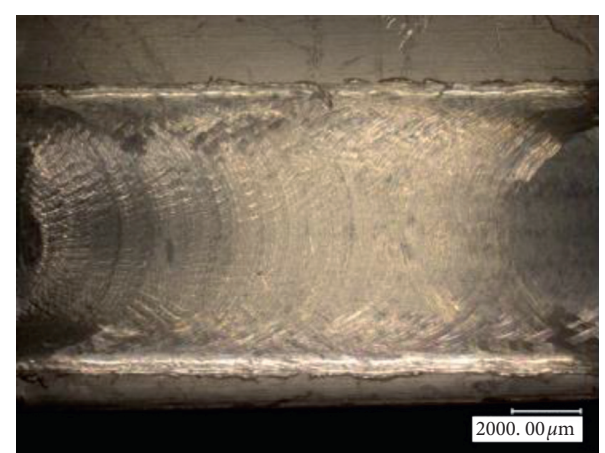

(b)

FIGURE 21: Comparison of workpiece surface topography with 20 times magnification. (a) UVARM. (b) CC.

ultrasonic vibration transforms the traditional way of continuous milling to a regular pulse-type cutting way, avoiding the generation of built-up edge, and the discontinuous contact between the tool and workpiece reduced the milling force and milling temperature, which consequently reduces the chip's influence on the finished surface and improves the surface quality of the machined surface.

The area of $0.2 \times 0.2 \mathrm{~mm}$ was selected as the scanning area on the processed workpiece surface. MICROMEASURE2 3D profiler was used to observe the 3D surface topography of the area and the image is taken as shown in Figure 22, where the feed per tooth is $6 \mu \mathrm{m}$. The spindle speed $r$ is $2000 \mathrm{~min}^{-1}$, and the ultrasonic amplitude $A$ is $15 \mu \mathrm{m}$. A close observation of Figure 22 shows that even with the same processing parameters, UVARM is quite different from that of conventional milling in terms of three-dimensional surface morphology. In the normal milling process, the surface of the processed surface is uneven. The UVARM process can perform periodic contact and separation between the milling cutter and the workpiece during its processing, and the machining process is not continuous. In addition, in the process of UVARM, due to the vibration of the workpiece, the tool will have the ironing effect on the processed surface, and the ironing effect can effectively reduce the metal residue on the surface, reduce the machining defects such as built-up edge, and further improve the surface quality of the processed surface. In addition, it can be found that the peak valley range of the surface morphology of the UVARM is $-5 \sim 5 \mu \mathrm{m}$ and the peak valley range of the surface morphology of conventional milling surface morphology is $-10 \sim 10 \mu \mathrm{m}$; this also shows that the surface quality of ultrasonic vibration milling can obtain better-machined surface than that of conventional milling.

It can be intuitively found from the observation above that the height of the peak valley fluctuation range of conventional milling surface is among $-6 \sim 6 \mu \mathrm{m}$, and compared with the conventional milling, UVARM surface peak valley range is small, the main distribution range is $-4 \sim 4 \mu \mathrm{m}$, and its height concentrated in the range of $-2 \sim 2$ $\mu \mathrm{m}$, significantly less than the peak valley range of conventional milling. It can be concluded that the surface quality of the UVARM is better than that of the conventional milling surface and thus verified the superiority of UVARM.
In this section, on the premise of fixing other experimental parameters, the influence of spindle speed on milling force during processing is analyzed and studied by selecting different spindle speeds. The specific experimental scheme and the final experimental data measured are shown in Table 6.

According to the experimental data obtained in Table 6, MATLAB was used to draw the behavior of machining surface roughness changing with spindle speed, and the difference between radial ultrasonic vibration-assisted milling and conventional milling was more clearly shown in Figure 23. It can be found that with the ultrasonic amplitude of $15 \mu \mathrm{m}$, feed per tooth of $6 \mu \mathrm{m}$, depth of cut of $0.3 \mathrm{~mm}$, when the spindle speed is changed, under the conventional milling condition, the machined surface roughness increases first and then decreased. But for the UVARM, the processing surface roughness parameter Sa decreases first and then increases, and the surface quality obtained from the UVARM is better than that of conventional milling surface except that the rotational speed is low. In particular, when the spindle speed is $800 \mathrm{~min}^{-1}$, the UVARM surface roughness is greater than conventional milling surface; this is due to the fact that when the spindle speed is low, the contact time between tool and workpiece is extended, resulting in an increase of the friction between the tool and the workpiece, and the chip scratches on the surface are more obvious. When the spindle speed is $1500 \mathrm{~min}^{-1}$, compared with conventional milling, the surface roughness parameter Sa of the UVAM processed surface decreases by $32.6 \%$. When the spindle speed is $2000 \mathrm{~min}^{-1}$, the surface quality obtained by UVARM is better than that obtained by conventional milling. When the spindle speed is higher than $2000 \mathrm{~min}^{-1}$, the surface roughness value obtained by UVARM gradually increases, while the surface roughness value obtained by conventional milling is keeping downward.

As shown in Figure 24, which shows the surface roughness of variation with each feed per tooth behavior, it can be found the machined surface roughness value of the UVARM is less than that obtained from conventional milling, and the decrease is $10.1 \%$. Specifically, when the feed per tooth is between $2 \mu \mathrm{m}$ and $4 \mu \mathrm{m}$, the difference between the two processing methods is small. The reason lies in that 


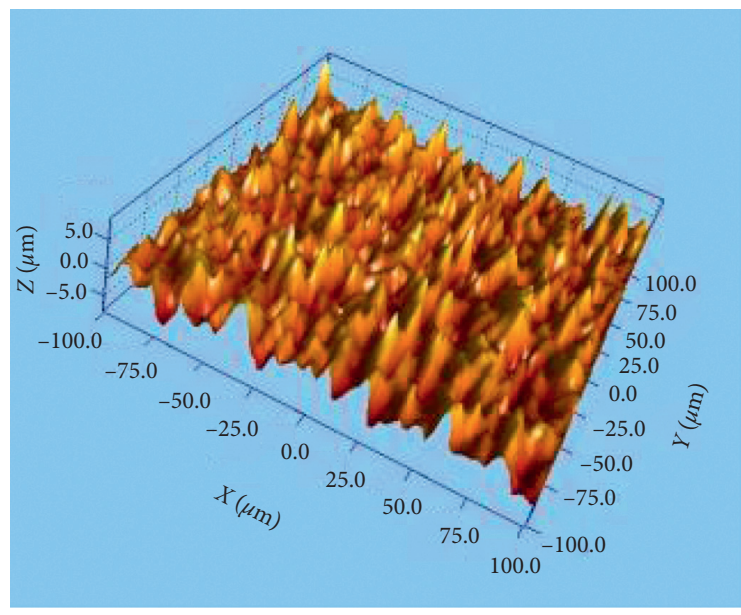

(a)

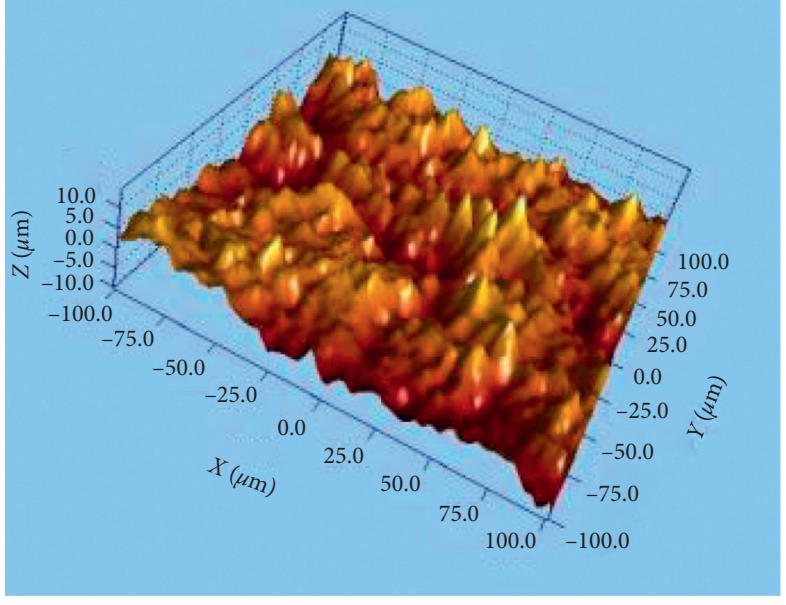

(b)

FIGURE 22: 3D topography contrast of workpiece surface. (a) UVARM. (b) CC.

TABLE 6: Experimental data (sequel).

\begin{tabular}{lcccccc}
\hline Case & $\begin{array}{c}\text { Feed per tooth } \\
(\mu \mathrm{m})\end{array}$ & $\begin{array}{c}\text { Feed rate } \\
(\mathrm{mm} / \mathrm{min})\end{array}$ & $\begin{array}{c}\text { Spindle speed } \\
\left(\mathrm{min}^{-1}\right)\end{array}$ & $\begin{array}{c}\text { Milling depth } \\
(\mathrm{mm})\end{array}$ & $\begin{array}{c}\text { Vibration amplitude } \\
(\mu \mathrm{m})\end{array}$ & $\begin{array}{c}\text { Surface roughness Sa } \\
(\mu \mathrm{m})\end{array}$ \\
\hline 9 & 6 & 45 & 2500 & 0.3 & 0 & 1.90 \\
10 & 6 & 14.4 & 800 & 0.3 & 15 & 1.87 \\
\hline
\end{tabular}

the feed rate of this stage is slight, so the material removal rate is not significant. When the feed per tooth is greater than $4 \mu \mathrm{m}$, the advantages of UVARM begin to stand out.

As shown in Figure 25, when the spindle speed is $2000 \mathrm{~min}^{-1}$, the feed per tooth is $6 \mu \mathrm{m}$, the depth of cut is $0.3 \mathrm{~mm}$, and the surface roughness parameter Sa obtained by conventional milling is $1.62 \mu \mathrm{m}$, which is obviously higher than that obtained by UVARM with the same processing parameters. When the ultrasonic amplitude is $10 \mu \mathrm{m} \sim 15 \mu \mathrm{m}$, the roughness value of the processed surface does not change significantly. However, in the process of ultrasonic amplitude increasing from $10 \mu \mathrm{m}$ to $25 \mu \mathrm{m}$, the roughness value of the processed surface has a downward trend. With the increase of amplitude, the intersecting phenomenon between the adjacent tracks of the cutting edge is relatively obvious, which makes it easier to chip breaking and chip removal, reduces the scratch phenomenon of the chip on the processed surface, and makes the processed surface smoother, thus reducing the roughness value of the processed surface. The impact of ultrasonic vibration on the surface roughness of the processed workpiece is gradually slowed down. In conclusion, the roughness of the processed surface has been significantly improved with the involvement of ultrasonic vibration. The reasons lie in that the UVARM adds ultrasonic vibration to the workpiece, which would lead to an ironing effect on the workpiece. Therefore, the built-up edge is reduced and the quality of the processed surface is improved. In addition, with the involvement of ultrasonic vibration, the traditional continuous milling method is changed into an intermittent cutting process, which

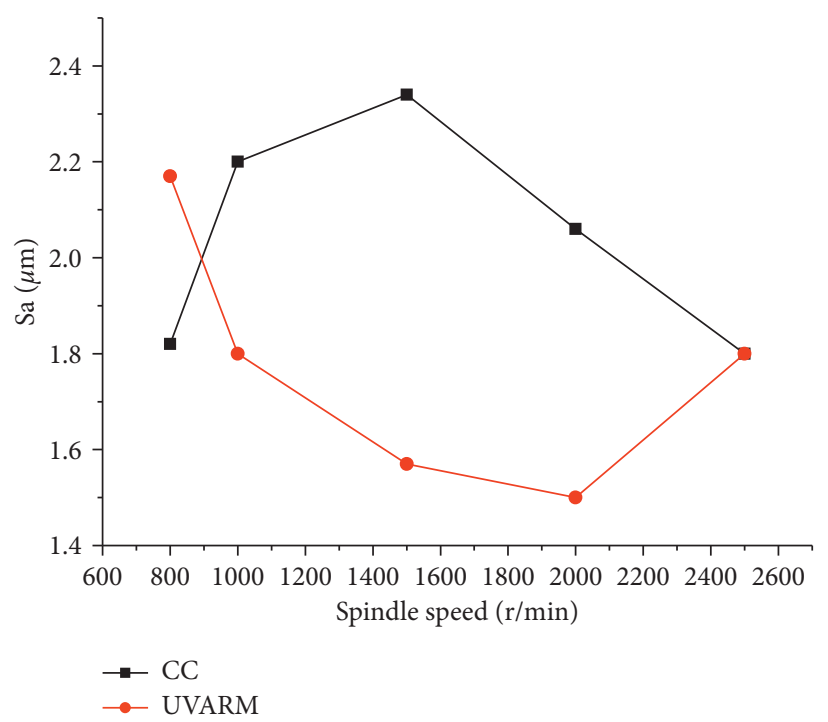

FIgURE 23: The behavior of surface roughness with the spindle speed.

effectively avoids the surface quality deterioration caused by the chip scratch on the processed surface.

In this section, the influence of ultrasonic amplitude on machining dimension precision during UVARM was studied by a single-factor experiment. Three repetitions of the milling process for groove generation are conducted in each group of the processing set. The workpiece is inspected using a VHX-1000E microscope. In order to avoid the effect 


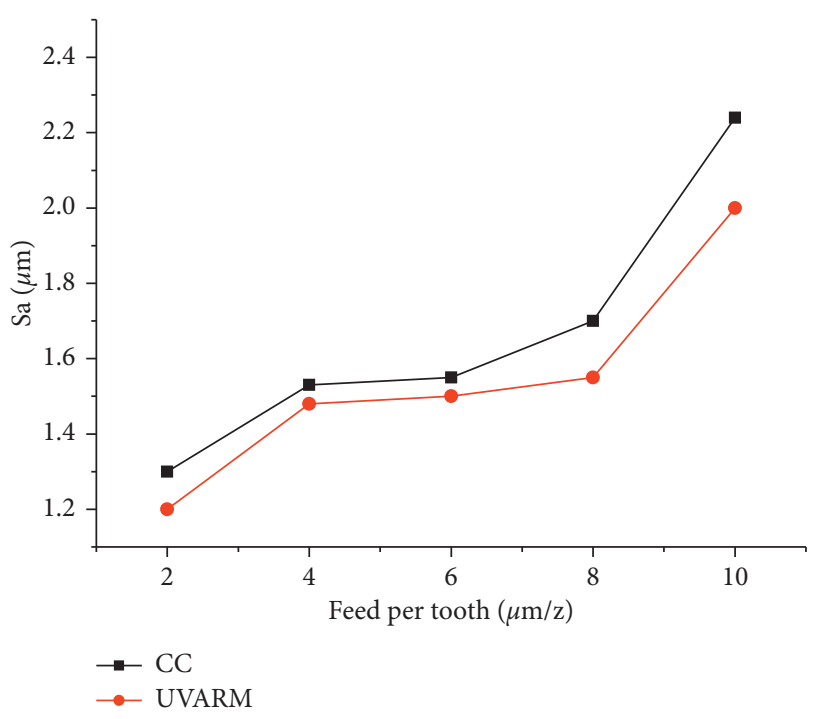

FIGURE 24: The behavior of surface roughness with the change of feed per tooth.

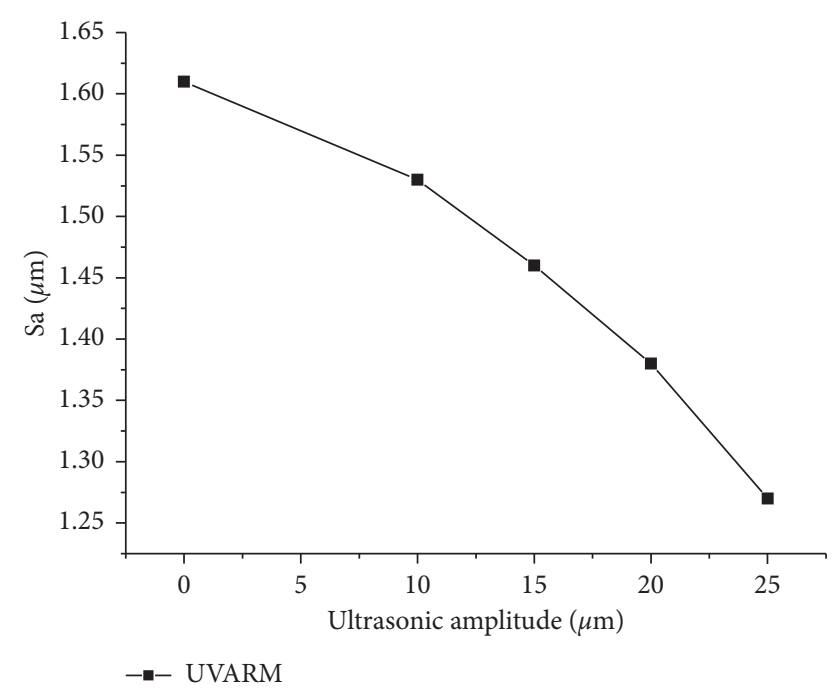

FIGURE 25: Surface roughness behavior with ultrasonic amplitude.

of the accidental error on the experimental results, five times of measurements are conducted on each machined workpiece. The average value of the measurement results is regarded as the groove dimension. The groove width and the ultrasonic vibration are plotted in Figure 26. It can be found that the dimensional accuracy of the groove is improved under the effect of ultrasonic vibration, and the dimensional accuracy of the groove is continuously improved with the increase of ultrasonic amplitude. This is due to the fact that the UVARM converts the traditional continuous milling process into an intermittent milling method. With the increasing of ultrasonic amplitude, the relative net cutting time is reduced. Therefore, in the milling process, the average milling force is reduced, which effectively avoids the dimension accuracy decreasing caused by the processing system being subjected to large force. Finally, with the effect of ultrasonic vibration, the dynamic displacement of the

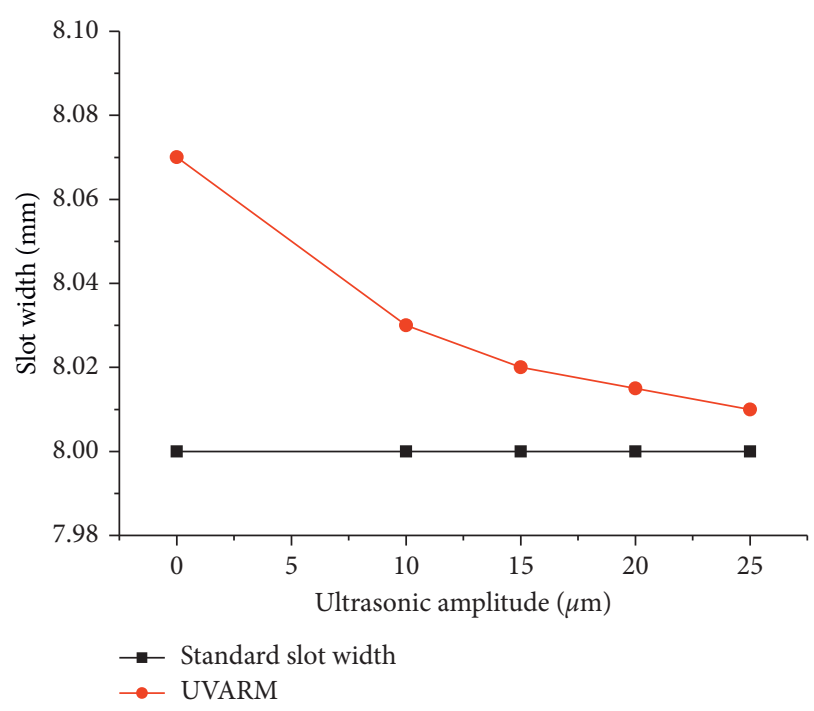

FIgURE 26: Dimensional accuracy of grooves under different amplitude conditions.

workpiece in the milling process decreases. The parts with high-dimensional precision can be obtained by appropriately increasing the ultrasonic amplitude.

\section{Conclusion}

In this paper, the UVA milling experiment setup is constructed. The material 6061-T6 is taken as the object to study the effect of cutting parameters on the experiment output, e.g., cutting force, workpiece surface roughness, and dimensional accuracy. The preliminary results can be summarized as follows. On the basis of the TH5650 type vertical machining center, the UVARM experimental setup is built by combining a special clamping device with the existing ultrasonic equipment. The experimental results also show that, with the increase of spindle speed, the milling force in both the CC and UVC experiments tends to increase. When the feed per tooth increased, the milling force isncreased. With the involvement of ultrasonic vibration, the milling force is significantly reduced, with the maximum reduction reaching $20 \%$. The comprehensive analysis showed that there was a decrease of about $10 \%$ to $25 \%$ in the ultrasonic case compared with the conventional method. Through a comparative study on the surface morphology of the $2 \mathrm{D}$ and $3 \mathrm{D}$ images of the processed surface, it is found that UVARM can inhibit the production of a built-up edge. With the ultrasonic vibration, the burrs on the processed surface are also reduced, and the grooves left by tool traces are shallower. Compared with conventional milling, the roughness value of the machined surface obtained by UVARM is reduced by $10 \%$ to $32 \%$. The experimental results also show that UVARM can effectively improve the dimensional accuracy of the workpiece. When ultrasonic amplitude increases from 0 to $10 \mu \mathrm{m}$, the groove width error decreases from $0.90 \%$ to $0.36 \%$, which has been significantly improved. When the amplitude increased from $15 \mu \mathrm{m}$ to 
$20 \mu \mathrm{m}$, the groove width precision decreased from $0.25 \%$ to $0.18 \%$. When the vibration amplitude was greater than $20 \mu \mathrm{m}$, it is not significant for the dimension accuracy improving led by the ultrasonic vibration.

\section{Data Availability}

The raw/processed data required to reproduce these findings cannot be shared at this time as the data also forms part of an ongoing study.

\section{Conflicts of Interest}

The authors declare that they have no conflicts of interest.

\section{Acknowledgments}

The authors acknowledge the financial aid and support from the National Natural Science Foundation of China (Grant no. 51875097).

\section{References}

[1] B. I. Polyak, E. V. Krivokorytov, G. S. Rossikhina et al., "Vibration milling of silicon carbide and sintered corundum," Glass \& Ceramics, vol. 54, no. 5-6, pp. 182-185, 1997.

[2] C. Y. Hsu, C. K. Huang, and C. Y. Wu, "Milling of MAR-M247 nickel-based superalloy with high temperature and ultrasonic aiding," International Journal of Advanced Manufacturing Technology, vol. 34, no. 9-10, pp. 857-866, 2007.

[3] V. Rok, S. Gašper, B. Peter et al., CIRP Annals - Manufacturing Technology, vol. 58, no. 1, pp. 143-146, 2009.

[4] D. Biermann, P. Kersting, and T. Surmann, "A general approach to simulating workpiece vibrations during five-axis milling of turbine blades," CIRP Annals, vol. 59, no. 1, pp. 125-128, 2010.

[5] J. Pujana, A. Rivero, A. Celaya, and L. N. López de Lacalle, "Analysis of ultrasonic-assisted drilling of Ti6Al4V," International Journal of Machine Tools and Manufacture, vol. 49, no. 6, pp. 500-508, 2009.

[6] K. Marcel, Z. Marek, and P. Jozef, "Investigation of ultrasonic assisted milling of aluminum alloy AlMg4.5Mn," Procedia Engineering, vol. 69, pp. 1048-1053, 2014.

[7] H. Gong, F. Z. Fang, and X. T. Hu, "Kinematic view of tool life in rotary ultrasonic side milling of hard and brittle materials," International Journal of Machine Tools and Manufacture, vol. 50, no. 3, pp. 303-307, 2010.

[8] T. Moriwaki, E. Shamoto, Y. Song, and S. Kohda, "Development of a elliptical vibration milling machine," CIRP Annals, vol. 53, no. 1, pp. 341-344, 2004.

[9] K. C. Fan, F. J. Shiou, K. M. Pan et al., "Design of a meso-scale 3-axis milling with nanometer accuracy," in Proceedings of the 36th International MATADOR Conference, pp. 161-164, Springer, Manchester, UK, July 2010.

[10] J. H. Ko, K. C. Shaw, H. K. Chua, and R. M. Lin, "Cusp error reduction under high speed micro/meso- scale milling with ultrasonic vibration assistance," International Journal of Precision Engineering and Manufacturing, vol. 12, no. 1, pp. 15-20, 2011.

[11] He Yu, Z. Zhou, P. Zou, X. Gao, and F. E. Kornel, "Study of ultrasonic vibration-assisted thread turning of Inconel 718 superalloy," Advances in Mechanical Engineering, vol. 11, no. 10, pp. 1-12, 2019.
[12] He Yu, P. Zou, Wu-Le Zhu, and K. Ehmann, "Ultrasonic elliptical vibration cutting of hard materials: simulation and experimental study," The International Journal of Advanced Manufacturing Technology, vol. 91, pp. 363-374, 2017.

[13] M. M. A. Zarchi, M. R. Razfar, and A. Abdullah, "Influence of ultrasonic vibrations on side milling of AISI 420 stainless steel," International Journal of Advanced Manufacturing Technology, vol. 66, no. 1-4, pp. 83-89, 2013.

[14] H. Ding, R. Ibrahim, K. Cheng, and S.-J. Chen, "Experimental study on machinability improvement of hardened tool steel using two dimensional vibration-assisted micro-end-milling," International Journal of Machine Tools and Manufacture, vol. 50, no. 12, pp. 1115-1118, 2010.

[15] H. Ding, S.-J. Chen, and K. Cheng, "Two-dimensional vibration-assisted micro end milling: cutting force modelling and machining process dynamics," Proceedings of the Institution of Mechanical Engineers, Part B: Journal of Engineering Manufacture, vol. 224, no. 12, pp. 1775-1783, 2010.

[16] H. Ding, S.-J. Chen, and K. Cheng, "Dynamic surface generation modeling of two-dimensional vibration-assisted micro-end-milling," The International Journal of Advanced Manufacturing Technology, vol. 53, no. 9-12, pp. 1075-1079, 2011.

[17] X. H. Shen, J. H. Zhang, H. Li et al., "Ultrasonic vibrationassisted milling of aluminum alloy," International Journal of Advanced Manufacturing Technology, vol. 63, no. 1-4, pp. 41-49, 2012. 